\title{
Development of a model of including historical and cultural landscapes in the tourist infrastructure
}

\author{
Natalia Shestopalova ${ }^{1}$, Antonina Riabchenkova ${ }^{1}$, and Svetlana Vershinina ${ }^{1, *}$ \\ ${ }^{1}$ Irkutsk National Research Technical University, 664074, Lermontova str., 83, Irkutsk, Russia
}

\begin{abstract}
The article is devoted to the issues of urban development of the coastal territories in the functional, architectural and planning, social and environmental aspects of design using the example of the island of Olkhon. Natural recreational resources are the basis for the development of tourism in the Baikal region, which include unique landscapes, and objects that have the status of natural monuments. The primary development of tourism in the basin of Lake Baikal is envisaged in all government planning and program documents. Historical and cultural heritage of the region, religion and ethnocultural features of indigenous peoples who have preserved the age-old traditions of nature management represent a special category of resources. Historical and cultural heritage includes socially recognized material and spiritual values preserved by the society for the maintenance of social and ethnic identity and for transmiting them to the next generations. This information potential of the territory, imprinted in phenomena, events, material objects, moral and ethical norms, scientific and philosophical ideas is necessary for the mankind for its future development.
\end{abstract}

The fact that the international community has accepted the concept of sustainable development has influenced the approaches to the development of tourism on Lake Baikal. The status of the lake as a place of the world nature heritage can be supported only provided that the environmental norms and requirements are strictly observed in the design, construction and operation of tourist and infrastructure facilities. Delicate joining the natural landscapes and historical and cultural environment will allow occupying and maintaining own niche on the global tourist market.

The forms of living traditional culture, reflecting the cultural ways and traditions of the living space arrangement by the people living in a certain territory are of particular interest among the objects of cultural heritage. Representatives of many ethnic groups live on the territory of the Baikal nature territory, and the most numerous of them are these of the Russian and Buryat ethnoses. Tolerance and peaceful coexistence of religions, harmonious interaction and interpenetration of cultures, common traditions, and customs of hospitality have a favorable impact on the development of tourism.

\footnotetext{
*Corresponding author: c06@istu.edu
} 
The purpose of the research is to analyze the state and prospects for the development of tourism, using the unique recreational potential of the historical and cultural landscapes of the Baikal region.

The tasks are the following:

1. Development of the concept of the arrangement of territories within the boundaries of municipalities, taking into account the preservation and restoration of the natural landscape, and reducing the anthropogenic load.

2. Creation of regulations and normative documentation that takes into account the preservation of the historical and cultural heritage of the Baikal nature territory in accordance with the traditions of peoples inhabiting the island of Olkhon.

3. Development of the coastal areas as a center of tourist activities on the island of Olkhon. Accomplishment of territories in accordance with the functional purpose of the land.

4. Popularization of the idea of civilized arrangement of natural territories and creation of the system for informing tourists about the existing rules of staying in the cult places and specially protected natural areas.

The Baikal nature territory can be considered as a cultural and landscape phenomenon related to the type of associative landscapes. In associative landscapes, the cultural component is often represented not in the material, but in the mental form, generating associations. In this case, the natural complex is included in the historical and cultural space without changing its natural rhythm and evolution, as a sacred, cult, and ritual place. These qualities are, in our opinion, the leading values of this territory. Such a complex existed here for quite a long time, as an equilibrium system of nature and cultural activity of man. Taking into account the importance of this place for understanding this territory as a repository of spiritual concentration and as a culturally significant phenomenon, we offer a conceptual vision of the development of this area with the orientation on the environmental forms of tourism as one of the most actively developing sectors of the global tourist industry. Sensible, environmentally and economically adjusted policy in the use of resources of the recreational territories, and development and adherence to the regime of "inexhaustible" nature management is the main condition of the environmental tourism. In this case, ecotourism is an important component of the sustainable development of natural areas.

Sustainable use of natural resources is the only permissible form of using natural resources within the boundaries of the national park, aimed primarily at increasing the incomes of the local population. The forms and volumes of such use should not cause irreparable damage to the protected natural objects and allow the annual restoration of the consumed resources through natural processes and / or through special supporting measures. The forms and volumes of sustainable use of natural resources should be established on the basis of scientific recommendations and monitoring data carried out by the national park.

In connection with this, a model territory, Olkhon Island, was chosen for the study. Olkhon is located in the central part of Lake Baikal, near the highest depth mark (1642m). All the varieties of natural landscapes of the Baikal shores are concentrated here. Even in its form it resembles the outline of Lake Baikal. The highest point is the mountain of Zhima (Izhmey) with a mark of $1274 \mathrm{~m}$. Olkhon is characterized by a special climate: the summer is hotter here and the winter is colder. There is less precipitation than anywhere else in the Baikal region, and strong winds are frequent in the autumn-spring period. The island is the geographical, historical and sacral center of the Lake, the focus of ancient historical legends. The island is rich in historical monuments. By their number per $1 \mathrm{sq} . \mathrm{km}$. it has no equal in all of the Baikal region: 143 archaeological sites are known here. These are burials, ancient fortifications, and remains of stone walls.

This work does not pursue consideration of the economic vector of development of the territory, suggesting that narrow specialists in this field will be engaged in this. The authors 
of the project proposals determined the primary tasks: settlement the flow of tourists and their awareness of the place they are visiting.

The following recommendations are relevant to the settlement of tourist flows:

- To restrict from visiting tourists historical and cultural sites associated with traditional beliefs, except for the necessary for the local population shamanic ritual activities;

- To create of a zone of silence where observational thematic areas are allowed, the additional function of which is informing and navigating visitors, cultivating a treacherous attitude to holy places and limiting the desire to visit places that are historically tabooed.

- To restrict movements (this applies to the water surface as well) on any motorized means (other than eco-friendly);

- To restrict free movements of livestock, which possess local residents.

The weakening of the influence of the active forms of recreation on the "silence zone" can be achieved by the rendering of functions related to entertaining elements of recreation into the residential area, behind a strip of afforestations. For this purpose, the resources of tourist bases and private farms located on the territory of the village of Khuzhir should be used;

- In the village of Khuzhir, to provide the minimum necessary conditions for the convenience and comfort of tourists, and to use the potential of the already existing tourist bases: houses, kitchens, toilets, showers, pavilions with various trade functions, including essential goods;

- For the organization of tourist trips, to develop several categories of environmental hiking trails. Routes of these trails can be aimed at the following groups of vistors:

A) The majority of visitors, including people with limited mobility (in this case, it is needed to use hardwood - wooden decking, suitable for wheelchairs, with a width of not less than $1800 \mathrm{~mm}$;

B) For visitors with a moderate level of preparation, with the use of natural cover with elements of insignificant arrangement;

C) For experienced travelers exploring remote and pristine natural areas assuming a long secluded stay and rare meetings with other visitors. Natural canvas trail without any signs of working on them should be arranged for such visitors.

- To implement the regime of "inexhaustible" nature management, tourists are to be provided with locally produced goods. For this purpose it is necessary to organize a network of shopping sites that will provide these services from the local population. The list of such goods can include food, local cuisine, crafts, clothing, utensils, and amulets.

- To actively involve the local population in servicing of tourists that will increase their level of employment and incomes (maintenance of hotels or stationary houses, cleaning of garbage and toilets, care and maintenance of horses and dogs, escorting on hiking trails, and maintenance of service stations);

To maintain the environmental infrastructure, it is necessary to provide the following:

- Treatment facilities, a system for recycling household garbage, etc.

- Barbecue areas can be organized only in the existing residential area, in the territories of tourist centers and private farmsteads.

A small territory for camping parking in the Saray Bay area can be allocated, and strict rules of stay there are to be introduced. The prohibition of the organization of fireplaces, and the obligation to use light stoves for cooking, and flashlights for lighting should be one of these rules. The visitors should be provided with an opportunity, if necessary, to rent all household utensils.

Also, it is necessary to restore once existing greenery: taking into account the historical information that the so-called Sacred Grove existed on the territory near Cape Burkhan, the project provides for the regeneration and restoration of vegetation at three taxonomic levels: cover vegetation in the form of fescue sheep and thyme as covers that retain moisture in the 
soil; the second level is the planting of shrubby hedge cotoneaster, cotoneaster malnocarpus and spiraea, as drought-resistant species growing on the crushed stone, creating protective functions for the survival and growth of the major large-sized trees; the third level is largesized trees like larch, most suitable to the conditions prevailing here.

Special recommendations on compliance with technology and the timing of planting (under strict supervision of specialists) are to be considered. These recommendations should be carried out under the strict guidance of specialists in this field. The duties of the employees of the tourist company and the leaders of organizations dealing with nature protection include the promotion of rules that do not allow deviations from the developed route and prescribe "to stay on the trail" (Figure 1).
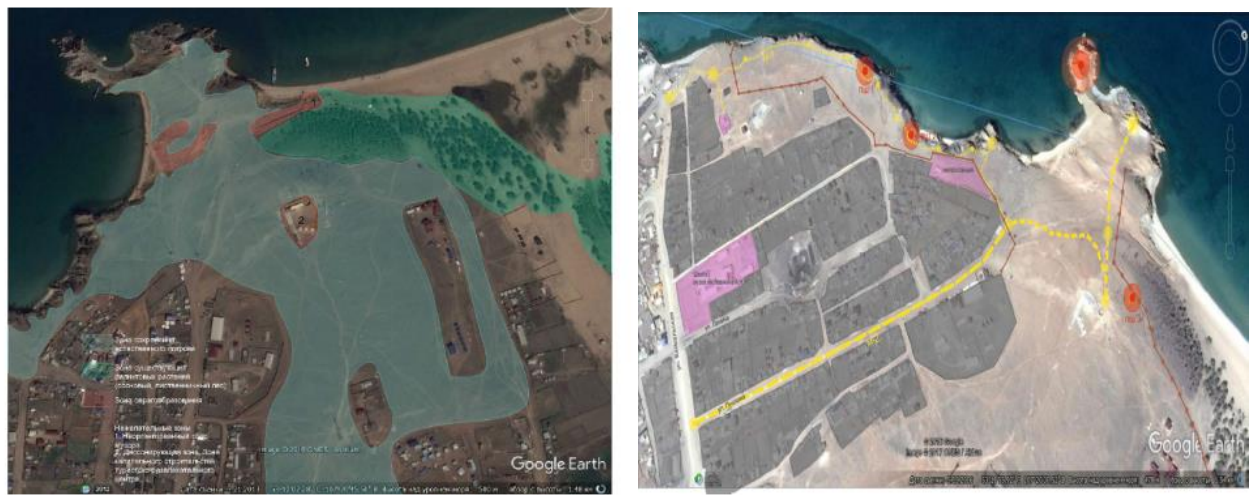

Fig. 1. An example of a functional-planning analysis of the landscape of the village of Khuzhir.

On the territory of the village of Khuzhir, it is necessary to allocate a special area for the maintenance, training and rental of horses. The inclusion of this function in servicing tourists will open additional opportunities for attracting disabled people or children with a violation of the central nervous system. For communication and rehabilitation, small groups and their accommodation in camp sites can be organized.

- Development of draft tasks, selection of methods and means of sanitary equipment for the creation of life support systems (ventilation, heating, lighting, microclimate optimization, removal and storage of manure, water supply of farms and watering animals, distribution of feed and feeding, etc.);

- Enterprises for the maintenance and training of horses should be provided with feed, mainly of own production, water, electricity, heat, and access roads, and separated from the nearest residential area by a sanitary protection zone (a break). The size of the sanitary protection zone should be taken depending on the capacity of the enterprise of the following sizes: up to 10 mares - $200 \mathrm{~m}$, from 10 to 20 mares $-300 \mathrm{~m}$.

- The land area belonging to the horse breeding enterprise should ensure the full utilization of all manure received, excluding dumping it on the surrounding area, in water and water protection zone.

Along the boundaries of the territory of the horse breeding enterprise, a green zone of wood plantations should be created. On the territory of the village of Khuzhir, the necessary zone for the maintenance and training of dogs for sleddings in harness should be provided.

The inclusion of this function in the service for tourists will open additional opportunities for attracting tourists in winter, and diversify their stay with the use of eco-friendly forms of recreation.

Conditions for the people with limited mobility. The size of the lanes and grounds on the pedestrian paths where wheelchair users and other low-mobility groups may be located should be appointed taking into account the following requirements: 
- the width of the strip for unilateral traffic must be at least $1.2 \mathrm{~m}$; for two-way traffic - at least $2 \mathrm{~m}$;

- for turning wheelchairs, a platform measuring $1.8 \times 1.8 \mathrm{~m}$ is required;

- for stop of the wheelchair users, a section of $0.9 \mathrm{~m}$ in width and $1.5 \mathrm{~m}$ in length is required, and for adults with prams $-0.9 \mathrm{~m}$ in width and $1.8 \mathrm{~m}$ in length;

- for the oncoming traveling of people in the wheelchairs, and also in the case of spaceterritorial opportunities, the broadening of the pedestrian path in the plan should be carried out in a size not less than: for comfortable pedestrian traffic conditions $-3.0 \times 1.8 \mathrm{~m}$; for normal pedestrian traffic conditions $2,0 \times 1,7 \mathrm{~m}$;

- the height of the passageway shall be not less than $2.1 \mathrm{~m}$ to the bottom of the structures and not less than $2.3 \mathrm{~m}$ to the ends of the branches of trees.

Transport and pedestrian network. The organized transport and pedestrian network on the territory of the village of Khuzhir is to be provided, taking into account strict restrictions of the "Silence Zone". Common transport and pedestrian communications are to be introduced that will eliminate the network of chaotically ragged roads. Rolling and trampling of the very vulnerable, difficultly restored vegetation of the island of Olkhon must be terminated.

1. To solve this issue, it is proposed to introduce one local main road and a network of secondary roads, which will have a two-way direction and a number of stopping points.

2. To organize and equip the central transport and transfer hub (near the monument), and two peripheral transport and transfer junctions (one at the beginning near the "small port", and the second one higher from the center along Baikalskaya street).

The main function of these hubs is a change from the city transport to a local one, and transfer to places of rest and sites. An additional function of the hubs is to inform tourists arriving to rest (obtaining information about free accommodations and informing about excursions, providing additional information on forms of the environmental mechanization like bicycles, horses, dog sleds, etc. rentals).

There are to be also located medical centers, authorized shopping places with local delicacies, souvenirs and other necessary things on vacation.

The services of travel agencies offering various organized, licensed recreation routes designed for different age and physiological opportunities for visiting tourists are to be provided here.

3. In the central zone of Khuzhir, the most important information point is to be organized for making acquaintance of visitors with local rules, customs and requirements. It is possible to call it as "the reference service" or "the old hut". The main function of such a service is information and navigation. It has to explain to visiting tourists the importance of the place and the associated restrictions (for example, pedestrian travel to a holy place).

4. For visitors on cars, it is necessary to organize a paid, well-maintained parking slot with a repair shop and a filling station or without it.

5. For low-mobility groups, the alternative modes of transport are to be offered, for example, comfortable vehicles harnessed by horses. The vehicles can be of various modifications, including those with the sites that wheelchair users can safely utilize, or cabins with soft comfortable sofas for elderly people who are very eager to travel, but are limited in movement due to health and old age. They can also be used by the families with small children or people just limited in time or loving comfortable travels. It would be very appropriate to use on the island modern modes of transport on air cushions or with special wheels that do not damage the soil and vegetation.

6. To provide a pier for small vessels with economic facilities, and the possibility to organize the rental of non-motorized vessels

7. To provide a runway for small aircrafts in the northern part of the village of Khuzhir. 
8. Along with the pedestrian routes and trails, it is proposed to introduce a route for nonmotorized mechanization, such as roller skates, bicycles of various modifications (two, three, four wheeled bicycles, with trailers in the form of trolleys for passengers and cargo).

9. To develop ecological paths (hiking routes that will be categorized according to the degree of preparedness of people - tourist and recreational ones, promenades, etc.)

The results of the study can be used in the development of land use regulations and the development of coastal areas (as zones with special restrictions of use). Planning techniques can be applied when developing the planning projects. Methodological guidelines can be included into the recommendations on the protection and use of historical and cultural monuments in the conditions of the development of tourism, on different territories, including on the island of Olkhon. The creation of a system of information for the guests of the island about the existing rules for staying in the cult places and specially protected natural areas with the possibility of replicating this system will allow regulating recreational flows.

\section{Refernces}

1. D. V. Bobryshev, S. E. Vershinina, Proceedings of the Irkutsk State Technical University, 12, 103-107 (2014)

2. D. V. Bobryshev, Proceedings of the Irkutsk State Technical University, 7, 22-28, (2011)

3. A. A. Lyapin, A. E. Shpirko, T. A., Golobokova, N. V. Shestopalova, Recommendations on the protection and use of historical and cultural monuments in the conditions of tourism development on the island of Olkhon (Irkutsk, 1997)

4. N. V. Klyushnichenko, Interexpo Geo-Siberia, 2, 185-190 (2007)

5. A. V. Bogoviz, S. V. Lobova, A. N. Alekseev, I. A. Koryagina, T. V. Aleksashina, Advances in Intelligent Systems and Computing, 622, 609-616 (2018)

6. N. V. Shestopalova, Historical and cultural landscapes, their development and preservation (IrSTU Publishing, Irkutsk, 2013)

7. A. V. Ryabchenkova, Proceedings of the Irkutsk State Technical University, 3 (86), 192-196 (2014) 